\title{
O papel do sujeito face à imagem. Interpretações estruturo-fenomenológicas: o caso de estudo das Pinturas murais de São Francisco de Bragança
}

Inês Afonso Lopes

\section{(2) OpenEdition \\ Journals \\ Edição electrónica \\ URL: http://journals.openedition.org/medievalista/834 \\ DOI: 10.4000/medievalista.834 \\ ISSN: 1646-740X \\ Editora \\ Instituto de Estudos Medievais - FCSH-UNL}

\section{Edição impressa}

Data de publição: 1 Janeiro 2012

\section{Refêrencia eletrónica}

Inês Afonso Lopes, «O papel do sujeito face à imagem. Interpretações estruturo-fenomenológicas: o caso de estudo das Pinturas murais de São Francisco de Bragança », Medievalista [Online], 11 | 2012, posto online no dia 26 fevereiro 2014, consultado no dia 06 maio 2019. URL : http://

journals.openedition.org/medievalista/834; DOI : 10.4000/medievalista.834

(C) IEM 
Título: O papel do sujeito face à imagem. Interpretações estruturo-fenomenológicas: o caso de estudo das Pinturas murais de São Francisco de Bragança.

Autor(es): Inês Afonso Lopes

Enquadramento Institucional: GAHOM, École des Hautes Études en Sciences Sociales

Paris; Departamento de Ciências e Técnicas do Património - DCTP (FL - UP)

Contacto: inesafonsolopes@gmail.com

Fonte: Medievalista [Em linha]. №11, (Janeiro - Junho 2012). Dir. José Mattoso. Lisboa:

IEM.

Disponível em: http://www2.fcsh.unl.pt/iem/medievalista/

ISSN: 1646-740X

\section{Resumo}

A historiografia, e consequentemente a historiografia da arte e das imagens, têm vindo, nas últimas décadas, a adoptar como corrente de investigação principal a designada antropologia histórica, herdeira dos trabalhos de autores como Marc Bloch, Fernand Braudel e Jacques Le Goff. No entanto, essa antropologia histórica tem sido alvo de várias críticas por seguir, muitas vezes, apenas a vertente associada à antropologia estruturalista fazendo desvanecer o papel dos agentes/actores. É na convergência destas dimensões de análise (estrutura e fenomenologia) que as novas correntes da antropologia histórica começam a encontrar um equilíbrio que permite um maior fortalecimento epistemológico.

A partir do caso de estudo das pinturas murais de São Francisco de Bragança pretendemos explorar não só o papel que a conjuntura histórica teve na sua realização, assim como a possível percepção que os sujeitos tiveram face às mesmas. Procuramos, desta forma, demonstrar que as obras de cultura material só se revestem de significado se tivermos em conta os sujeitos que com elas interagem.

Palavras-chave: Pintura Mural, S. Francisco de Bragança, Antropologia da Imagem, Devoção, Idade Média. 


\section{Abstract}

The historiography and its role concerning the art and images, throughout the last decades are adopting as the main way of investigation the so called historical anthropology, as heritage of the works from writers like Marc Bloch, Fernand Braudel e Jacques Le Goff. Notwithstanding, that historic anthropology has been targeted from several criticisms, owing the fact that often it is only focused on the structural anthropology rather than watching the role of its agents/actors. Upon the axis of convergence of such analytical dimensions (structure and phenomenology), the new guiding lines of historical anthropology, start to find a balance, which allows the development of a greater epistemological richness.

From the use of the case of study of the murals of S. Francisco de Bragança Convent, we intend to explore not only the role that the historical circumstances played on its achievement, but also how the involved people possibly understood the same.

Therefore, using that example, we intend to demonstrate that material artwork only find its meaning when we also look after the people actually involved, who really had interacted with it.

Keywords: Wall-painting, S. Francisco de Bragança, Image Anthropology, Devotion, Middle Ages. 


\title{
O papel do sujeito face à imagem. Interpretações estruturo-fenomenológicas: o caso de estudo das
}

\section{Pinturas murais de São Francisco de Bragança}

\author{
Inês Afonso Lopes
}

\section{Algumas questões em torno das metodologias no estudo da imagem medieval}

Nas últimas décadas temos assistido a um intenso e renovado interesse pelo corpus da pintura mural religiosa portuguesa. Trabalhos de autores como Luís Urbano Afonso ${ }^{1}$ e Paula Bessa $^{2}$, entre outros, têm permitido o conhecimento deste corpus que, antes do apogeu dos retábulos barrocos, foi essencial na estruturação/decoração do espaço sacro.

Este reavivar da historiografia da arte portuguesa em relação ao estudo das pinturas parietais é essencial na reconstrução da memória. Depois das empreitadas de renovação dos espaços religiosos, que acompanharam paulatinamente os gostos do seu tempo ${ }^{3}$, hoje são sobretudo os académicos que têm a percepção da importância que a pintura mural outrora teve como medium para a devoção e culto nas igrejas. Nesse sentido, trabalhos (não só de índole historiográfica mas, também, campanhas de restauro que tem sido levadas a cabo para o conhecimento do corpus material da pintura mural) que

\footnotetext{
1 Neste sentido, veja-se a tese de Mestrado dedicada às Pinturas Murais de S. Francisco de Leiria publicada pelos livros Horizonte: As Pinturas Murais da Igreja do Convento de São Francisco de Leiria. Lisboa: Livros Horizonte, 2003. E a sua tese de Doutoramento (obra que fez um vasto levantamento à grande maioria do corpus de pintura mural do País) -A Pintura Mural Portuguesa entre o Gótico Internacional e o Fim do Renascimento. Formas, Significados, Funções.

${ }^{2}$ Pintura Mural no fim da Idade Media e inicio da Idade Moderna no Norte de Portugal defendida na Universidade do Minho em 2007.

${ }^{3}$ E que apagaram ou obliteraram as pinturas pré-existentes.
} 
ponham à luz a quantidade, diversidade e funções destas pinturas são essenciais para a recuperação de uma memória colectiva ${ }^{4}$ sobre este tema.

No reavivar desta memória colectiva será importante um conjunto de abordagens diversas ao objecto que permitam, na sua convergência, criar uma percepção, a mais completa possível, da importância que a pintura mural de índole religiosa outrora teve. Quem foram os seus destinatários? Que oficinas as realizavam? Quais as suas principais estruturas formais? Como se processava a migração das suas formas, suas temáticas e programas a elas associados? Que lugar/papel estas ocupavam no espaço sacro? Qual a sua relação com a liturgia e os rituais? Como eram utilizadas enquanto imagens de devoção? Qual a sua função nas mediações sociais em que participavam? Estas e outras questões terão de ser respondidas e/ou alargadas por vários estudos dos quais já possuímos grandes contributos como os acima referidos.

Abordar a pintura mural dentro de uma epistemologia ligada à antropologia da imagem poderá ser uma via de trabalho prolífera. Hans Belting na obra Pour une anthropologie des images define uma metodologia a assumir para o estudo da antropologia da imagem $^{5}$ a partir da análise da complementaridade imagem-medium-corpo. Aplicar esta metodologia no âmbito do estudo das imagens medievais, poderá fornecer-nos importantes instrumentos para uma reflexão sobre o seu verdadeiro significado e práticas a ela associadas - a imagem medieval era antes de mais um aparelho complexo onde as trocas semânticas com o sujeito jogavam um papel crucial $^{6}$ na sua função. $\mathrm{O}$ nível de análise proposto por Belting parece-nos bastante completo porque foge à habitual abordagem levada a cabo pela antropologia histórica ${ }^{7}$ herdeira da vertente estruturalista de Lévi-Strauss ${ }^{8}$. Esta visão estruturalista, imposta na construção historiográfica das últimas décadas, cria uma barreira opaca para a percepção do papel do sujeito face aos fenómenos tornando, portanto, a análise destes incompletos. É nesse

\footnotetext{
${ }^{4}$ Sobre o conceito memória colectiva consultar Maurice HALBWACHS - La mémoire collective. Paris: Albin Michel, 1997.

${ }^{5}$ Perspectiva mais tarde desenvolvida pelo mesmo autor na obra La vraie image: croire aux images?, Paris: Gallimard, 2007.

${ }^{6}$ BASCHET, Jérôme - L'iconographie médiévale. Paris : Gallimard, 2008.

7 Como ela é trabalhada por Jacques Le Goff em obras como o « Nascimento do Purgatório".

${ }^{8}$ ANHEIM, Etienne «Art, littérature et anthropologie historique. Quelques réflexions historiographiques ». L'Atelier du Centre de recherches historiques. [Em linha]. $\mathrm{N}^{\circ} 6$ (2010) [Consultado dia 8 de Abril de 2011] Disponível em 3 de Julho de 2010
} 
sentido, que as novas teorias, tanto ligadas à antropologia como à antropologia histórica, seguem a partir das propostas dos antropólogos Vincent Descombes, Alban Bensa e Jean Bazin, bem como de sociólogos como Pierre Bourdieu ${ }^{9}$, Howard Becker ou PierreMichel Menger ${ }^{10}$. Urge, portanto, criar um campo de análise onde se esbata a distinção entre as representações e as práticas. Ou seja, analisar os fenómenos sociais (neste caso a partir de uma análise historiográfica) não só como testemunhos e partes integrantes de uma estrutura mas, também, repensar os possíveis efeitos que estes provocam(aram) nos sujeitos participantes (re)produtores dessa mesma estrutura.

É nesse sentido, que as teorias de Belting (principalmente a ideia da complementaridade imagem-medium-corpo) parecem convergir. Belting defende que na analogia entre o medium (estrutura) e o corpo (sujeito), poderemos encontrar a percepção primeira dos sujeitos ${ }^{11}$. No entanto, este autor também refere que o papel do sujeito tem que ser visto com ressalvas. Belting refere a ideia de "uso subjectivo das imagens", ou seja, na imagem ocorre uma projecção de um conjunto de associações pessoais de cada sujeito ${ }^{12}$. Ao mesmo tempo o medium ligado à imagem (no fundo, um arquétipo) revela a estrutura que envolveu todo o processo de criação e da percepção da imagem material; para este autor o conceito essencial para a percepção da imagem material é sempre o medium. No entanto, para Belting estas trocas semânticas são complexas sendo que se baseiam numa dialéctica tripartida que revela as dimensões estruturais/históricas ${ }^{13}$, estas envolvidas sempre por um processo de crença sobre cada elemento ${ }^{14}$. Portanto, análise da imagem material não estará completa sem o seu arquétipo e os sujeitos que a produzem e percepcionam ligados a partir do medium - ponto essencial em toda esta rede semântica.

\footnotetext{
9 ALBERT, J.-P. «L'histoire et l'anthropologie : convergences et spécificités ». L'Atelier du Centre de recherches historiques. [Em linha]. No6 (2010) [Consultado a 8 de Abril de 2011] Disponível em 7 de Maio de 2010. Para aprofundar a síntese feita por Bourdieu entre estrutura e acção consultar BOURDIEU, Pierre - Esboço de uma teoria da prática: precedido de três estudos etnologia Cabila. Oeiras: Celta Editores, 2002.

${ }^{10}$ ANHEIM, Etienne - Op. Cit.

${ }^{11}$ BELTING, Hans - Pour une anthropologie des images. Paris : Gallimard, 2004, p.35

${ }^{12}$ BELTING, Hans - L'Image et son Public au Moyen Age. Paris : G. Monfort, 1998, pp.2-3

${ }^{13}$ BELTING, Hans - Pour une anthropologie des images. Paris : Gallimard, 2004, p.43

${ }^{14}$ BELTING, Hans - La vraie image: croire aux images ?, Paris: Gallimard, 2007, p.31
} 
Articulados com as teorias de Belting, os trabalhos de Jérôme Baschet (muito em concordância com a teoria das imagines medievas de Jean-Claude Schmitt), relativamente à análise da imagem medieval, mostram-nos uma visão não só concorrente com a de Hans Belting mas também complementar a esta. Baschet a partir do conceito chave de imagem-objecto ${ }^{15}$ exprime as complexidades da imagem nas suas relações com o sujeito e estrutura. Este autor vê a imagem não só como uma representação do real (ideal), mas principalmente como produtora de uma realidade sensível que (re)produz um imaginário ${ }^{16}$ no sujeito. Este imaginário, por sua vez, será operante na criação de outras realidades (imaginadas ou reais) onde as imagens terão mais uma vez um papel fulcral. A imagem-objecto tem, assim, a capacidade de interagir com o imaginário e portanto com o corpo $^{17}$, o que a dota o imaginário de uma materialidade sensível.

Seguindo o conceito de imagem-objecto, tal como é utilizado por Baschet, a importância da inter-relação entre imagem, lugar e ritual é fulcral para as funcionalidades da imagem (bem como dos outros agentes referidos). A localização das imagens poderá dotá-las de novos sentidos, ao mesmo tempo que a relação entre várias imagens no mesmo espaço é um factor essencial na conexão mental que estas exercem com o sujeito. Por outro lado, quando a imagem é anexada/complementar aos ritos esta não só imprime ao rito uma maior complexidade como este dota, também, a imagem de novos imaginários que aumentam tanto o seu impacto ${ }^{18}$ como o seu efeito mnemónico $^{19}$.

Mais uma vez as teorias de Baschet demonstram a importância da convergência entre o papel da estrutura (história, mitos e representações) e a acção dos sujeitos (com o modo como o seu imaginário interage com o exterior e a estrutura). Este método parece, pela sua riqueza epistemológica, ser eficaz para abordar a pintura mural - o seu estudo, como acima referido, engloba várias abordagens, no entanto, se procurarmos analisá-la sob o

\footnotetext{
${ }^{15}$ Expresso no seu artigo : Introduction : L' Image-Objet in. SCHMITT, J.-C. e BASCHET, J. (Coord.) L’Image. Fonctions et usages des images dans l'Occident médiéval. Paris : Le Léopard D’or, pp.7-26. E mais tarde desenvolvido, principalmente na introdução do livro de BASCHET, Jérôme - L'iconographie médiévale. Paris: Gallimard, 2008.

${ }^{16}$ BASCHET, Jérôme - L'iconographie médiévale. Paris : Gallimard, 2008, p.9

${ }^{17}$ Idem, Ibidem, p.59

${ }^{18}$ Idem, Ibidem, p. 100

${ }^{19}$ Sobre esta ideia consultar a obra:SEVERI, Carlo - Le principe de la chimère : une anthropologie de la mémoire. Paris: Éd. Rue d'Ulm (Musée du Quai Branly), 2007.
} 
ponto de vista da antropologia da imagem esta abordagem terá de ter uma complementaridade das duas dimensões de análise já referidas (estrutural e fenomenológica), de modo a conseguir-se uma aproximação mais completa à possível ontologia $^{20}$ que englobou a produção destas imagens.

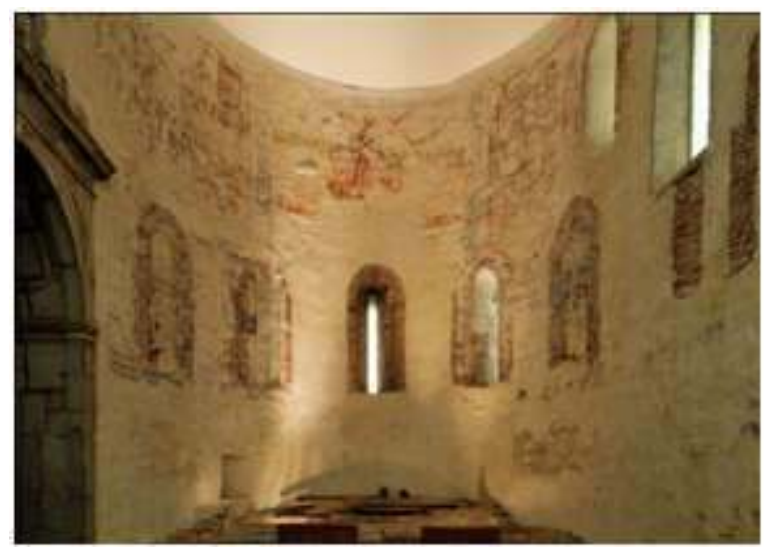

Fig.1 - Capela-Mor da Igreja do Convento de São Francisco de Bragança.

A pintura mural sacra medieval - objecto de estudo profundamente prolífero do ponto do ponto de vista antropológico - pode ser vista como meio de sacralização do espaço em que está inserida, adjuvante/convocadora e memorial de rituais, (re)produtora de devoções e cultos, mediadora de relações verticais entre o visível (terrestre) e o invisível (mundo sagrado), e por sua vez das transacções e relações sociais que estas geram $^{21}$. No entanto, para um estudo completo sob este prisma seria necessário um trabalho mais vasto do que um artigo nos permite. Esboçaremos apenas a partir de um estudo de caso uma metodologia que pensamos poder ser útil para o estudo da pintura mural a partir de um objecto de estudo definido - as pinturas murais da capela-mor da Igreja de São Francisco de Bragança.

20 Segundo Philippe Descola as ontologias projectam-se e interagem com as imagens: DESCOLA, Phillippe - "Manieres de voir, manières de figurer ». In DESCOLA, Philippe (Coord.), La Fabrique des images. Visions du Monde et formes de la représentation. Paris: Somogy (Musée du quai Branly), 2010, p.17

${ }^{21}$ BASCHET, Jérôme - Op. cit., p.49

Medievalista online № 11 | Janeiro - Junho 2012 @ IEM - Instituto de Estudos Medievais 7

www2.fcsh.unl.pt/iem/medievalista 


\section{As pinturas Murais da Capela-Mor da Igreja de São Francisco de Bragança - algumas abordagens teóricas à pintura mural}

Descoberto por detrás de um retábulo barroco na capela-mor da Igreja de São Francisco de Bragança, na década de 80 , encontra-se um conjunto de pintura mural, que pelo seu interessante programa e grande qualidade formal suscita o interesse de vários investigadores. Enquadrado na cabeceira da igreja, que Luís Urbano Afonso refere como sendo do segundo quartel ou meados do século XIII, as pinturas murais são datadas pelo mesmo autor por volta de $1520^{22}$. Estas cobrem toda a superfície muraria da cabeceira da capela-mor num sentido horizontal. Visto o desconhecimento da sua existência e, portanto, a falta do seu culto e devoção, as imagens encontram-se num estado bastante degradado que não permite, como seria desejável, fazer uma leitura iconográfica de forma completa. Pensamos, no entanto, que a partir do corpo fragmentário que nos resta será possível reconstruir parte da linguagem que este programa emanou na referida dialéctica imagem-medium-corpo no seu espaço e tempo de produção, quando estas foram alvo de devoção e culto.

A composição é realizada por duas bandas horizontais que ocupam toda a capela-mor. Se a primeira banda (no sentido de leitura descendente) é dividida em três registos verticais com diferentes representações em cada, já a segunda banda é mais difícil de definir tematicamente. Esta é ritmada por pelo menos seis arcadas falsas, que no interior possuem imagens de filactérias com inscrições e figuras masculinas (uma de maiores dimensões no centro de cada arcada e outras mais pequenas relativamente à primeira), as quais alguns investigadores identificam com os Profetas ${ }^{23}$, enquanto outros definem como os Apóstolos ${ }^{24}$. Pelo grau de danificação bastante alargada desta parte do programa das pinturas, deixaremos de parte qualquer tipo de interpretação para não cair em análises do tipo especulativo.

\footnotetext{
${ }^{22}$ AFONSO, Luís Urbano -"Manter a Freguesia no século XVI: Os frescos de São Francisco de Bragança e a Virgem da Misericórdia.". Cadernos Terras Quentes, n², (2005).

${ }^{23}$ Por exemplo Luís Urbano Afonso (tanto na sua tese de Doutoramento com no artigo acima referido).

${ }^{24}$ Paula Bessa coloca a dúvida se puderam ser os Profetas ou os Apóstolos, inclinando-se mais para a hipótese dos Apóstolos pelo número de nichos existentes - BESSA, Paula - Pintura Mural no fim da Idade Média e início da Idade Moderna no Norte de Portugal. 2007, p.255-256; tese defendida na Universidade do Minho.
} 
Ficaremos então, pela primeira banda de representações. Se pensarmos a partir do conceito de iconografia inaugurado por Panofsky ${ }^{25}$, podemos identificar três temas; no entanto dúvidas assistem-nos em relação a dois deles - o Juízo Final e a Jerusalém Celeste - sendo a Mater Omnium o único tema que identificamos com certeza. No lado do evangelho encontra-se lateralmente uma representação que os vários investigadores que já trabalharam estas pinturas costumam considerar uma imagem do Juízo Final; no centro uma imagem da Mater omnium; e do lado da epístola uma representação que, corroborando a atribuição de Luís Urbano Afonso, nos parece uma imagem da Jerusalém Celeste.

Estas imagens encontram-se na capela-mor, o local mais importante do espaço sacro. Este espaço pela sua polarização leva, tanto o leigo como o clérigo, a focarem-se na dinâmica axial e assim convergir na abside sacralizada, sendo por isso aí que ocorrem os principais rituais para coesão do sistema religioso ${ }^{26}$.

Nesse sentido, é importante o enfoque dado a estas imagens no lugar ritual - a colocação topográfica da imagem dentro do espaço sacro transforma-o sendo a imagem adjuvante da hierarquização dos micro-espaços dentro deste, o que contribui para as representações sociais no espaço ${ }^{27}$.

Como já referimos, a procura de uma interpretação iconográfica ou iconológica não é o que pretendemos retirar destas imagens. Procuramos, antes, repensar/reflectir sobre os possíveis efeitos no sujeito que as vivenciou enquadrado no seu tempo e espaço de produção e devoção - a cidade de Bragança no final da Idade Media portuguesa. Tendo em conta a envolvência do sujeito, qualquer estudo dirigido a uma vertente iconológica seria pouco verosímil. Se bem que é um facto que o método instaurado por Panofsky, relacionado com a análise iconográfica e iconológica é bastante eficaz, quando se fala de produções artísticas ${ }^{28}$ realizadas para um público de maior erudição, o sujeito a que se destinavam as pinturas murais de Bragança vivia uma realidade bastante diversa. Se a corrente iconográfica e iconológica vai muitas vezes buscar a raiz do seu método às

\footnotetext{
${ }^{25}$ Não procuramos sem dúvida fazer uma análise do nível iconográfico ou iconológico, no entanto usamos esta terminologia, pela sua grande divulgação, para melhor definir as temáticas das pinturas.

${ }^{26}$ BASCHET, Jérôme - Op. cit., p.99

${ }^{27}$ Idem, Ibidem, pp.99-100

${ }^{28}$ Para perceber a diferenciação entre produções artísticas e imagens de devoção e culto consultar BELTING, Hans - Image et culte : une histoire de l'art avant l'époque de l'art. Paris: Ed. du Cerf, 1998
} 
fontes teológicas, os laboratores e mesmo grande parte do clero do mundo medievo, não interiorizavam a racionalidade teológica de uma forma directa, a sua visão da religião/realidade invisível era um misto entre a produção teológica e as crenças locais ${ }^{29}$ mais ligadas a um mundo mágico que racional ${ }^{30}$ (a distinção entre estas duas dimensões só se torna estanque após o período designado por Iluminismo ${ }^{31}$ ). Corroborando esta ideia, Michel Camille afirma que após vários anos de estudo das imagens medievais, percebeu que a utilidade do método iconológico para a compreensão destas seria diminuta, visto este estudar essencialmente o conteúdo das imagens e não o seu poder face ao sujeito ${ }^{32}$.

O mesmo autor na obra citada ao nomeá-la Gothic Idol Ideology and image-making in Medieval Art expressa no título toda a ironia da imagem gótica na sua relação com a teologia criada em seu torno. Enquanto a teologia condenava de uma forma directa a idolatria das imagens, as práticas relacionadas com estas eram bastante diversas. Segundo Richard Marks os iletrados não sabiam distinguir o signo do sinal - o material do imaterial - (apesar de esta diferenciação entre letrados e iletrados, no que refere a crenças, não ser assim tão clara), estes eram levados à adoração através da referência "carnal" das imagens ${ }^{33}$ que objectivavam os seus "ídolos". A devoção dos crentes era primeiramente espoletada pela empatia com a imagem e não pela função didáctica que lhe seguiria ${ }^{34}$.

Mas qual era o papel da devoção neste mundo onde o tangível/intangível, visível/invisível coexistiam numa sociedade onde a crença era um dos elementos base da coesão social? Segundo Hans Belting, o dom é sempre o que sobressai na devoção sendo que, quando se trata da devoção relacionada com a imagem, a sua função didáctica referente ao além encontra-se sempre em segundo plano. A promessa de intercessão presente na imagem reveste-a de importância, pois ela é para o crente a personificação da entidade divina, permitindo um contacto imediato (quando visível ou

${ }^{29}$ LORD, Peter - The visual culture of Wales: Medieval Visions. Cardiff: University of Wales Press, 2003, p. 156

${ }^{30}$ BELTING, Hans -Pour une anthropologie des images. Paris : Gallimard, 2004, p.34

${ }^{31}$ Idem, Ibidem, p.34

32 CAMILLE, Michael - The Gothic Idol: ideology and image-making in Medieval art. Cambridge: Cambridge University Press, 1989. Prefácio, XXVI

${ }^{33}$ MARKS, Richard - Image and devotion in late medieval England. Stroud: Sutton, 2004, p.26

${ }^{34}$ Idem, Ibidem, p. 27 
invisível desde que se saiba da sua presença) entre o crente e o objecto da sua devoção numa acção dinâmica que Belting define como dynamis ${ }^{35}$. Nesse contacto com a imagem votiva e de devoção há um presente pleno de passado (acreditar na "divindade" pela sua mitografia) e de devir (na promessa do dom que advêm da nossa devoção) esta imagem representa uma história do passado e promete um futuro ${ }^{36}$. Nesse sentido, a importância da função didáctica prende-se ao conhecimento da mitografia que deu poder à imagem (no fundo ligada ao arquétipo da "divindade"). Por outro lado, a mitografia (ligada ao didatismo) presente nas imagens pressupõem uma revelação sobre o além. Ora, pode-se inferir que a importância do conhecimento das mitografias e normativas do além está também ligada à ideia de reversibilidade de méritos, no sentido em que quanto melhor interiorizarmos a lógica do além e seguirmos as suas normas, a comunicação com a imagem será mais completa e, portanto, o dom e contra-dom mais eficaz ${ }^{37}$.

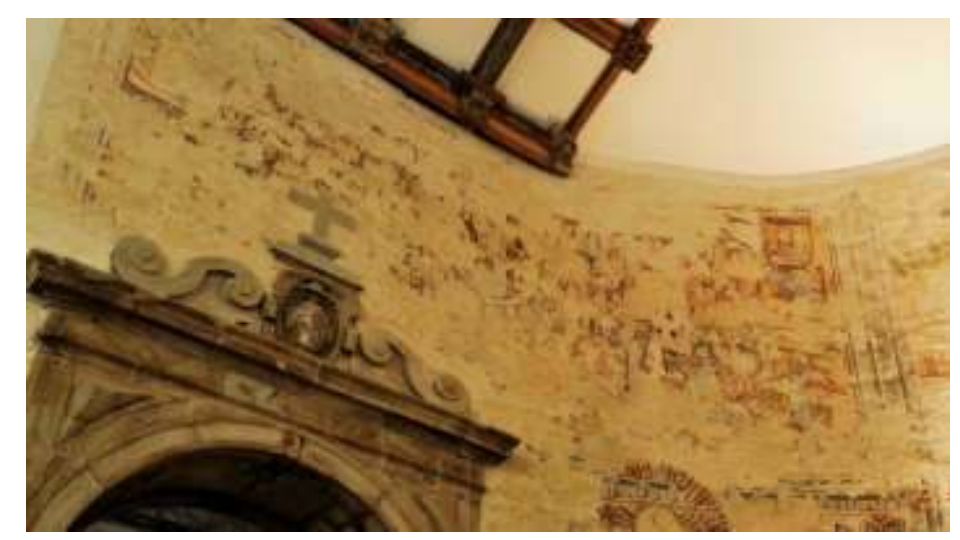

Fig.2 - Capela-mor da Igreja do Convento de São Francisco de Bragança - pintura mural representando cena escatológica.

\footnotetext{
${ }^{35}$ BELTING, Hans - Image et culte : une histoire de l'art avant l'époque de l'art. Paris: Ed. du Cerf, 1998, p. 15

${ }^{36}$ Idem, Ibidem, p. 20

${ }^{37}$ Idem, Ibidem, p. 17
} 


\section{Uma representação escatológica como imagem e devoção?}

No caso das pinturas murais de Bragança podemos ver o arquétipo anteriormente referido: nelas parece haver uma mensagem de dom e contra-dom inerente à devoção (materializada na Mater omnium, imagem de devoção por excelência). Estas demonstram um passado ligado à mitologia cristã (no sentido em que as cenas presentes são representações de várias mitografias, expressas nas escrituras e crenças, onde uma ideia escatológica cristã sobressai), mas, ao mesmo tempo, apresentam um presente/devir (na intercessora Mater omnium) em forma de esperança que se concretizará numa imagem de um futuro próspero (na Jerusalém Celeste). Um elemento neste programa, joga como pedra de toque: a representação que tem sido vindo denominada de Juízo Final. O Juízo Final era factor de medos que paradoxalmente também poderia conter uma mensagem de esperança como nota Jérôme Baschet ${ }^{38}$, visto nele poder estar a condenação ou a bem-aventurança.

O Juízo Final dentro da concepção de tempo linear cristão é também um elemento ligado a uma projecção do futuro (neste caso ligado à escatologia). Futuro este, incerto no sentido em que era desconhecido o momento em que este decorreria, e pela impressibilidade do seu desfecho para a alma individual do crente (factor que começava a ter cada vez mais peso com a desenvoltura do purgatório ${ }^{39}$ ), tornando-se, assim, um factor de incertezas e de medos, com necessidade de serem apaziguados. Tema bastante comum nas representações da Baixa Idade Média, o que demonstra a importância que este tinha para Homem desta época, a incerteza nele contida dava à Igreja um grande poder de dominação como afirma Jérôme Baschet $^{40}$. No entanto, na representação bragantina parece ter um carácter um pouco diverso.

\footnotetext{
${ }^{38}$ BASCHET, Jérôme - Op cit., p.84

${ }^{39}$ Para perceber o papel do Purgatório no modo diverso de percepção do conceito de alma individual consultar: LE GOFF, Jacques - O Nascimento do Purgatório, Lisboa: Editorial Estampa, 1993 e FOURNIÉ, Michelle - Le ciel peut-il attendre? Le culte du purgatoire dans le Midi de la France (v. 1320-v. 1520).Paris : Les Éd. du Cerf, 1997.

${ }^{40}$ BASCHET, Jérôme - La civilisation féodale. De l'an mil à la colonisation de l'Amérique. Paris : Flammarion, 2006, p. 467
} 
Pelo que os fragmentos nos permitem analisar, podemos, com alguma certeza afirmar que a representação da condenação presente em muitos Juízos Finais (muitas vezes na forma de Inferno e peso das almas) não existe na representação de Bragança. O "Juízo Final de Bragança" é apenas constituído pela representação de Cristo (da sua figura só podemos ver as chagas das quais jorra sangue) com a mandorla, rodeado pela Corte Celestial (de onde fazem parte vários Santos e mesmo frades franciscanos identificados pela tonsura e vestes); anjos que carregam as Arma Christi e anjos com trombetas que parecem acordar os mortos que se encontram em túmulos por baixo da figura de Cristo. Toda a composição (rectangular) é enquadrada pelos quatro evangelistas que se encontram escrevendo - provavelmente os respectivos Evangelhos - (identificados pelos nomes inscritos em filacteras) distribuídos pelos quatro vértices o que dá um carácter narrativo (no sentido de uma acção no seu devir) a uma composição que parece à partida bastante estática. Jérôme Baschet denomina estas representações onde Cristo aparece triunfante (numa dimensão intemporal como designa o autor), acompanhado pela corte celeste, para assinalar o fim dos tempos, de teofania gloriosa ${ }^{41}$. Este autor considera que os Juízos Finais só podem ser considerados como tal, quando tem o elemento de julgamento neles contido, que se expressa na divisão entre condenados e bem-aventurados ${ }^{42}$, o que não acontece em Bragança ${ }^{43}$. Concordamos, portanto, por isso, com o autor e pensamos não se poder considerar a temática de Bragança um Juízo Final. Podemos, sim, ver nesta representação um híbrido entre imagem de devoção e narrativa (dimensão que poderia ser usada durante os sermões para aludir ao Juízo Final). Toda a sua composição aponta para isso. O que sobressai da imagem é Cristo num hierático e frontal para uma leitura fácil do espectador circundado por uma vasta Corte Celestial em posição orante ${ }^{44}$, o que poderá jogar um papel importante na percepção da imagem.

\footnotetext{
${ }^{41}$ BASCHET, Jérôme - Les justices de l'au-delà. Les représentations de l'enfer en France et en Italie (XII ${ }^{\mathrm{e}}-\mathrm{XV}^{\mathrm{e}}$ siècles). Rome : École Française de Rome Paris : 1993, pp.140-142

${ }^{42}$ Ibidem, p. 139

${ }^{43}$ Deixamos a ressalva que a composição não é totalmente visível, no entanto por uma análise cuidada do seu corpus parece-nos não existir essa divisão.

${ }^{44}$ Quando nos referimos a posição orante falamos, não da posição assumida com os braços elevados como no inicio da cristandade, mas sim a posição de mãos postas ao nível do peito.
} 


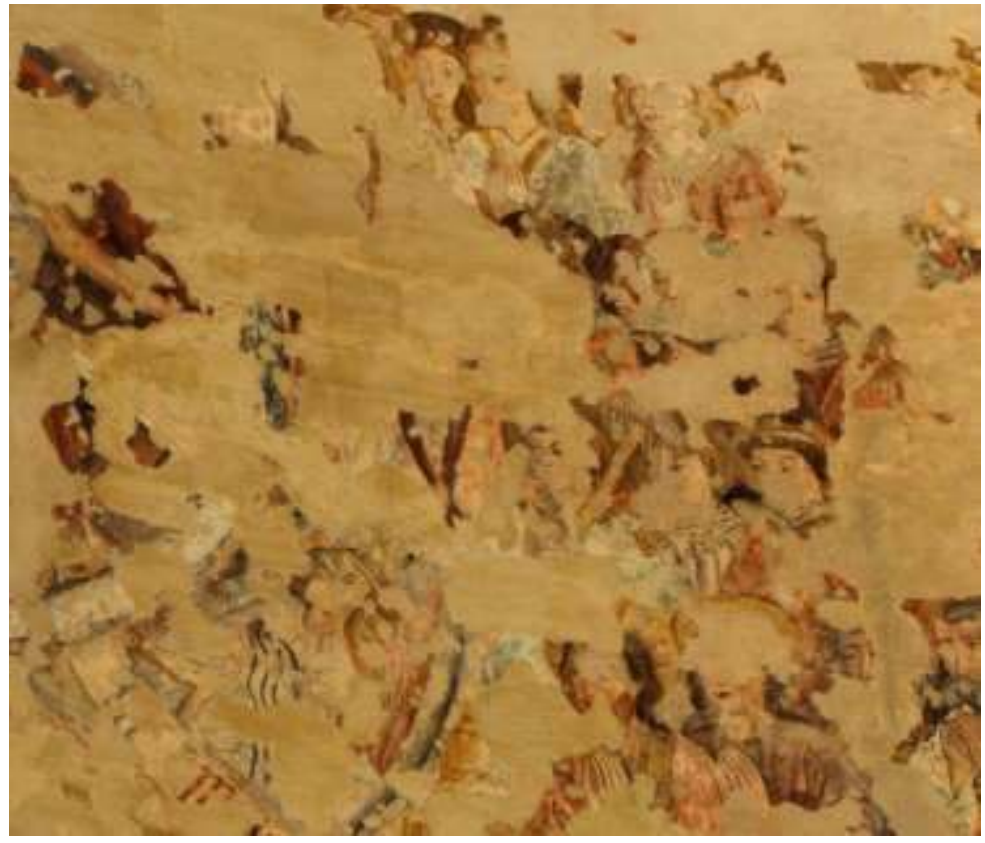

Fig.3 - Capela-mor da Igreja do Convento de São Francisco de Bragança - Cena escatológica (pormenor com Cristo; Anjo com Arma Christi e Corte Celestial em posição orante).

A importância da representação do gesto como factor de empatia com as imagens foi estudada por Jean-Claude Schmitt ${ }^{45}$,David Freedberg e Vittorio Gallese ${ }^{46}$ entre outros. Todos os investigadores sublinham a importância da visão da representação do gesto para o interiorizarmos e para o reproduzirmos ${ }^{47}$. A representação da figuração de imagens em posição orante viradas para um Cristo triunfal (com as chagas - símbolo do seu sacrifício - e rodeado das Arma Christi) poderá levar a uma empatia do crente com esta cena e apelar ao seu affectum devotionis a partir da interiorização da posição orante (o facto de entre a corte celestial estarem tantos frades franciscanos poderá concorrer, também, para esta ideia, para além do óbvio interesse - dentro de lógicas de propaganda religiosa - de se representar frades franciscanos na corte celestial num convento franciscano). Ao mesmo tempo, a presença dos túmulos (com defuntos ressuscitados e também em posição orante) e dos anjos com trombetas que acordam os mortos remete,

\footnotetext{
${ }^{45}$ SCHMITT, Jean-Claude - La raison des gestes dans l'Occident médiéval. Paris: Gallimard, 1990

${ }^{46}$ FREEDBERG, David e GALLESE, Vittorio "Motion, emotion and empathy in esthetic experience". Trends in Cognitive Science, Vol. 11, $n^{\circ}$ 5, (2007), pp.197-203.

${ }^{47}$ Segundo Schmitt, na Idade Media os gestos exteriores eram considerados o espalho de uma alma "domesticada", nesse sentido, estes eram importantes como demonstração da devoção individual e colectiva. SCHMITT, Jean-Claude - La raison des gestes dans l'Occident médiéval. Paris: Gallimard, 1990.p. 18
} 
sem dúvida, para a ideia escatológica de final dos tempos que, segundo a doutrina referida, levaria ao Juízo Final ${ }^{48}$. Por outro lado estas duas figurações dão a esta representação um carácter de narratividade que poderá torná-la profundamente ambígua e, nesse sentido, fácil de manipular conforme o discurso do orador, o rito ou imaginário do próprio espectador.

\section{A desenvoltura de uma devoção/culto a partir da propaganda religiosa: a Mater Omnium.}

Se a imagem daquilo que, corroborando as teorias de Baschet, chamamos uma Teofania (com as ressalvas que poderá ser visto também, e de acordo com a situação/ sujeito com que interage como um Juízo Final) se reveste de ambiguidade, no sentido em que poderá ser vista como uma imagem de devoção e, ao mesmo tempo, como prelúdio para uma cena narrativa do conhecimento comum, a imagem central desta série - a Mater omnium - também pode ser analisada como uma imagem ambígua (mais uma vez dependendo da percepção do sujeito que a via). A imagem representa a Virgem numa perspectiva frontal e hierática sendo coroada por anjos. Por cima encontra-se uma filactera com a inscrição “ MATER MISERICORDIE MISERE NOBIS”. Esta abre o seu manto azul, preso por um firmal, deixando antever por debaixo deste várias figuras que representam diferentes categorias sociais da época. São representados reis com a sua corôa, bispos com a sua mitra, homens e mulheres de vestes mundanas, um frade Franciscano (que segura no cinto da Virgem), bem como, paradoxalmente (tendo em conta que a pintura se encontra num convento Franciscano), um frade Dominicano. É interessante notar a topografia da Virgem do Manto nestes frescos. Esta encontra-se no centro desta série (no ponto côncavo da abside), por cima do olhar do observador. Ora, esta posição é considerada por Richard Marks como privilegiada pois é um foco para a visualização, e desta forma serve melhor os ritos e o diálogo como o crente ${ }^{49}$. No claro papel como imagem de devoção, desta figuração, poderá também ser extremamente importante a sua posição central na cabeceira que permite a melhor visão/apropriação

\footnotetext{
${ }^{48}$ Para esta concepção contribui, também, a ideia de que as imagens interagem entre si, o que leva a pensar que a Jerusalém celeste do lado da epístola da capela-mor poderá ser um seguimento ao Juízo Final.

${ }^{49}$ MARKS, Richard - Op. cit., p. 21
} 
pelo espectador. No entanto, o seu papel poderá ser mais ambíguo, não podendo, assim, apenas ser vista a partir da ideia de imagem de devoção ${ }^{50}$ segundo as denominações de autores como Panofsky e Hans Belting.

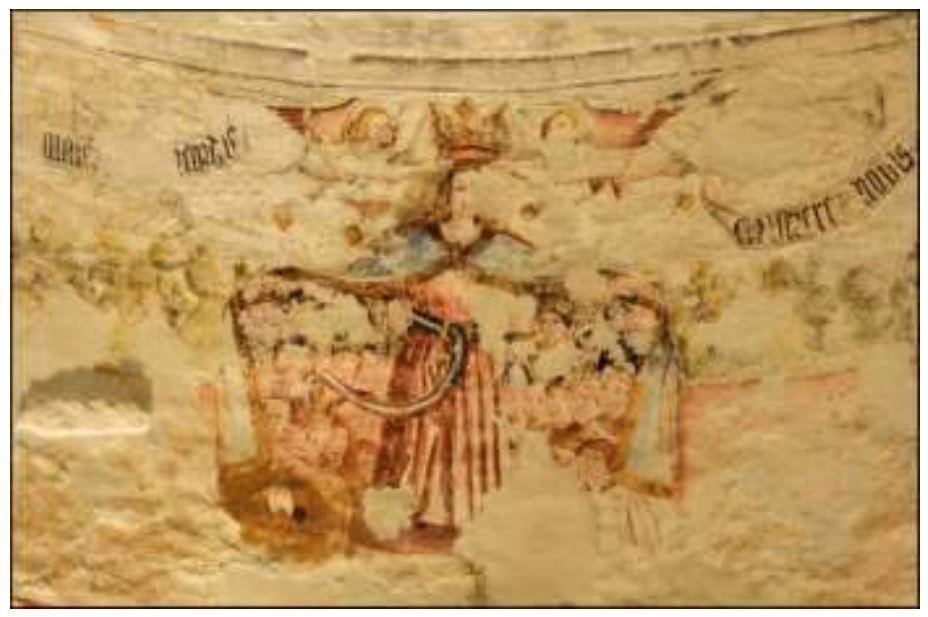

Fig.4 - Capela-mor da Igreja do Convento de São Francisco de Bragança - pintura mural da Mater Omnium.

Falamos de ambiguidade, quando nos referimos a esta representação, porque podemos colocar sobre análise dois prismas de percepção do sujeito: por um lado uma imagem que auxiliava a propaganda religiosa, por outro, uma imagem de devoção que contribuísse para o sentimento de protecção do crente. Será, nesse sentido, interessante analisar como o arquétipo desta imagem foi inicialmente construído para auxiliar a propaganda religiosa e como no decorrer das suas práticas começou a ser usada como imagem devocional.

O papel da Virgem como intermediária entre Deus e os Homens desenvolve-se na Baixa Idade Média. Com o desenvolvimento do culto cristológico desenvolve-se, também, o culto ao "instrumento" desta incarnação - A Virgem Maria. O seu papel protector é apresentado e reproduzido, não só pelas imagens, mas também em vários textos, tanto numa vertente dita erudita como popular, estes últimos de língua vernacular (o que em

\footnotetext{
${ }^{50}$ Para perceber este conceito consultar as obras :PANOFSKY, Erwin - Peinture et dévotion en Europe du Nord à la fin du Moyen âge. Paris: Flammarion, 1997 e BELTING, Hans - L'Image et son Public au Moyen Age. Paris: G. Monfort, 1998.
} 
muito auxiliou o seu culto $^{51}$ ). É, portanto, natural que as ordens religiosas numa perspectiva de concorrência naquilo a que podemos chamar "mercado religioso" tentassem demonstrar alguma preferência dada pela Virgem à sua ordem: a preferência da Rainha dos Céus garantiria a eficácia da ordem na "protecção espiritual” dos crentes $^{52}$. São, portanto, abundantes os relatos que demonstram a predilecção da Virgem por uma determinada ordem, assim como várias imagens que ajudaram a desenhar um pensamento figurativo ${ }^{53}$ em relação a esta ideia, o que ajudou a desenvolve-la no imaginário colectivo ${ }^{54}$. Um dos modos de a Virgem mostrar protecção por uma determinada ordem era a utilização de símbolos apotropaicos, taumatúrgicos e profiláticos, que seriam apropriados pela ordem ${ }^{55}$, sendo dentro desta ideia que o manto da Virgem se encontra.

Segundo Jean Delumeau o manto é arquetipicamente um símbolo de protecção desde a antiguidade $^{56}$. Este símbolo foi usado no século XIII pelo monge Cisterciense Césaire de Heisterbach, para demonstrar a predilecção da Virgem pelos Cistercienses na sua emblemática obra Dialogus Miraculorum - uma colecção de 746 exemplares, escritos entre 1217 e $1222^{57}$. O texto é uma glorificação à ordem de Cister sendo que no Livro VII, dedicado à Virgem Maria, o último capítulo desenvolve uma história intitulada “Ordinem cisterciensem Monacho sub Mariae pallio vidit in regno caelorum”. Neste texto Césaire de Heisterbach revela a sua visão de um monge cisterciense que, vendo o sequito da Virgem (onde não se encontravam monges cistercienses porém membros de outras ordens) este lhe pergunta, onde estão os cistercienses entre o seu séquito. Esta replica, que aqueles lhe são tão queridos que estão por baixo do seu manto, deixando

\footnotetext{
${ }^{51}$ Veja-se as Laudas e cantigas do mestre André Dias publicadas por Mário Martins: MARTINS, Mário Laudes e cantigas espirituais de Mestre André Dias. Roriz: Mosteiro de Singeverga, 1951, principalmente da página 6 à 120 .

52 DONADIEU-RIGAUT, Dominique - Penser en images les ordres religieux, XIIe-XVe siècles. Paris : Éditions Arguments, 2005

${ }^{53}$ Para compreender esta ideia consultar: DONADIEU-RIGAUT, Dominique - Penser en images les ordres religieux, XIIe-XVe siècles. Paris: Éditions Arguments, 2005

${ }^{54}$ Ora vejamos o Escapulário no caso dos Carmelitas.

${ }^{54}$ DELUMEAU, Jean - Rassurrer et Protéger. Le sentiment de sécurité dan l Occident d'autrefois. Paris: Fayard, 1989, pp. 263-264

54 DONADIEU-RIGAUT, Dominique «Les ordres religieux et le manteau de Marie ». Cahiers de Recherches Médiévales, (2001)

${ }^{55}$ Vejamos o Escapulário no caso dos Carmelitas.

${ }^{56}$ DELUMEAU, Jean - Op. cit., pp. 263-264

57 DONADIEU-RIGAUT, Dominique «Les ordres religieux et le manteau de Marie ». Cahiers de Recherches Médiévales, (2001)
} 
entrever, nesse momento, um grupo de monges brancos sob o seu manto ${ }^{58}$. É demonstrada, deste modo, a importância da protecção da Virgem a uma ordem, em detrimento das outras - esta lenda é nitidamente uma apologia à ordem cisterciense, perceptível quando é feita menção ao especial carinho que a Virgem tem por esta ordem.

Esta imagem da Virgem do Manto foi-se espalhando em representações iconográficas a partir do século XIV. Estas eram inicialmente ligadas apenas aos Cistercienses, no entanto, desenvolveram-se para as outras ordens religiosas, como é o caso da representação de Bragança onde aparecem ordens mendicantes como os dominicanos e, principalmente, os franciscanos (o monge franciscano encontra-se do lado direito em relação à Virgem e segurando o seu cinto, o que à partida lhe dá maior contacto com o corpo sagrado).

Luís Urbano Afonso refere a importância desta propaganda religiosa no contexto bragantino pela recente (relativamente à datação das pinturas apontadas pelo autor) instauração da Santa Casa da Misericórdia nesta cidade (1518) ${ }^{59}$. A Santa Casa da Misericórdia, em muito ligada às confrarias, desenvolvia o espírito Franciscano de aproximação às populações urbanas mais desfavorecidas e uma inculcação de uma devoção ligada à piedade popular. O seu emblema principal era a Mater Omnium que se havia desenvolvido da fórmula ligada às ordens religiosas e começava a apresentar-se como protectora também dos laboratores - sendo redenominada de Virgem da Misericórdia. Ora, segundo Luís Urbano Afonso, o apropriar pelos franciscanos da principal bandeira das Misericórdias poderia evitar a perda dos seus clientes no

\footnotetext{
58 «Un moine de notre ordre, qui avait une dévotion particulière pour Notre-Dame, fut, il y a quelques années, ravi en esprit, et admis à contempler le ciel de gloire. Ayant vu les divers ordres (ordines) de l'Église triomphante, les Anges, les Patriarches, les Prophètes, les Apôtres, les Martyrs, les Confesseurs, et, répartis selon leurs insignes, les Chanoines Réguliers, les Prémontrés, les Clunisiens, il s'inquiéta de son ordre à lui (de suo ordine). Et il regardait de tous côtés, et ne découvrait aucun des siens dans le Royaume de Gloire. Alors se tournant vers la bienheureuse Mère de Dieu, il gémit et lui dit : "Pourquoi donc, Dame très sainte, ne vois-je ici personne de Cîteaux ? Pourquoi les plus dévoués de vos serviteurs sont-ils exclus de ces béatitudes?" Et la Reine du Ciel lui répondit: "Ceux de Cîteaux me sont au contraire si chers et si familiers que je les réchauffe sous mes bras" (sub ulnis meis foveam). Et ouvrant le manteau (pallium) qui la couvrait et qui était d'une largeur merveilleuse, elle lui montra une multitude innombrable de moines (innumerabilem multitudinem monachorum), de frères convers et de nonnes. Lui, plein d'une grande joie, rendit grâces, et son esprit ayant réintégré son corps, il raconta à son abbé ce $q u$ 'il avait $v u$ et entend $u^{58}$. » Cit. DONADIEU-RIGAUT, Dominique - Op. cit.

${ }_{59}$ AFONSO, Luís Urbano "Manter a Freguesia no século XVI: Os frescos de São Francisco de Bragança e a Virgem da Misericórdia”. Cadernos Terras Quentes, n², (2005)
} 
"mercado religioso" "60. Estes reverenciam ainda mais a imagem da Virgem do Convento de São Francisco (tão semelhante à das Misericórdias) pela antiguidade do culto e sacralidade deste Convento, sendo esse um ponto a favor dos franciscanos.

É neste momento que entra a importância desta imagem como imagem devoção para o crente. Jean Delumeau estuda o papel da imagem da Virgem Mater Omnium/Misericórdia no sentimento de segurança no ocidente a partir do século XIV $^{61}$. Para este facto temos de ter em conta que na crença comum o manto protegia das flechas da peste tornando-se a Virgem do Manto, juntamente com São Sebastião, protectora de uma Europa assolada pela peste negra ${ }^{62}$. Independentemente da conjuntura ligada à peste, a Virgem foi o patrono mais comum, tanto das almas individuais como da comunidade de crentes a partir do século XII ${ }^{63}$, multiplicando-se em várias iconografias que corresponderiam a crenças e superstições ligadas ao dia-a-dia da comunidade/crente que interiorizaria a imagem conforme as suas próprias vivências e necessidades ${ }^{64}$. A Virgem do Manto passa, assim, de protectora das ordens religiosas, para a protectora das novas comunidades de crentes - aglutinadas em confrarias tornando-se, por fim, a protectora por excelência do corpus social da cristandade ${ }^{65}$. Assim, a Virgem passa a significar o entrelaçar das várias categorias sociais construindo uma imagem global do corpo social onde os oratores coabitavam com os laboratores ${ }^{66}$.

\footnotetext{
${ }^{60}$ Idem, Ibidem

${ }^{61}$ DELUMEAU, Jean - Op cit., p. 261

${ }^{62}$ RIGAUX, Dominique - Une mémoire pour l'avenir : peintures murales des régions alpines = Una memoria per l'avvenire : pitture murali delle regioni alpine. Novara: Interlinea, 1997, p.174

${ }^{63}$ MARKS, Richard - Op. Cit..p.38; também na análise das Laudes e cantigas do Mestre André Dias esta aparece como protectora das almas para o Paraíso “ Ajudanos senhora e nos conforta, e se falecermos nos conporta e nos conduz, aa porta do teu reyno, honde tu es verdadeira luz, que todo peccador guya e aduz ao logar muyto dino, que he a gloria do parayso, e porem roga por nos sempre ao teu Jhesu Christo, que nos leve ao seu reyno glorioso e infinito, ámen." ( fls. 40-40 v.) MARTINS, Mário - Laudes e cantigas espirituais de Mestre André Dias. Roriz: Mosteiro de Singeverga, 1951, p.121

${ }^{64}$ Sobre esta ideia de uma perspectiva mais ligada à antropologia consultar CHRISTIAN, William A. Religiosidad local en la España de Felipe II. Madrid: Nerea, 1991.

${ }^{65}$ Para está ideia contribuíram imagens da Virgem do Manto difundidas em obras de larga difusão como no SPECULUM HUMANÆ SALVATIONIS: http://danielmitsui.tripod.com/aaaaa/bpbig/shs157.jpg, ou noutra edição, http://www.biblical-art.com/artwork.asp?id_artwork=21630\&showmode=Full\#artwork ${ }^{66}$ DONADIEU-RIGAUT, Dominique - Penser en images les ordres religieux, XIIe-XVe siècles. Paris : Éditions Arguments, 2005.p.49
} 


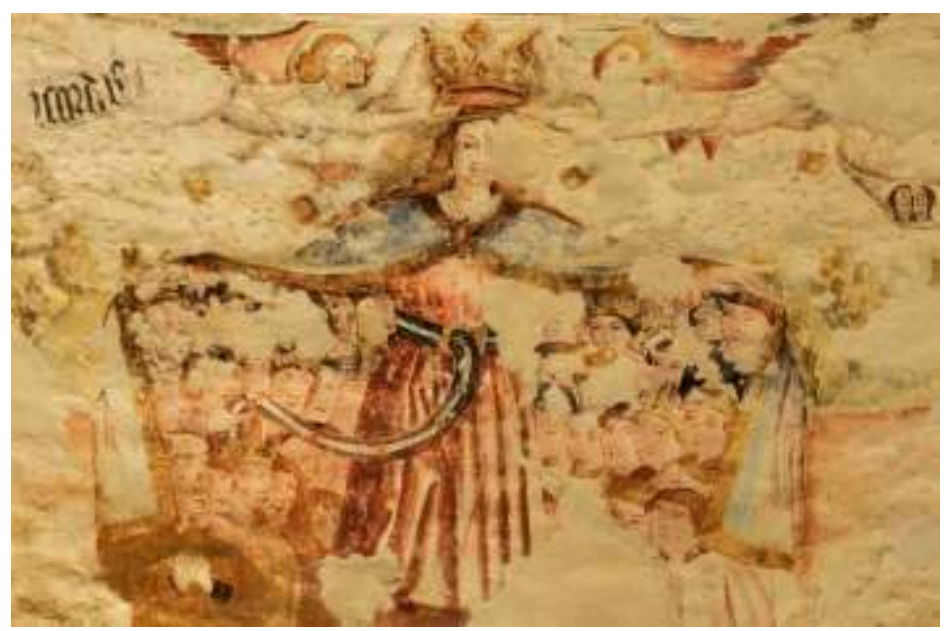

Fig.5 - Capela-mor da Igreja do Convento de São Francisco de Bragança - pintura mural da Mater Omnium (pormenor).

Nesse sentido, encontramos na Virgem do Manto de Bragança um papel interessante. Como já referimos, esta apresenta uma postura hierática e frontal que permitiria a fácil visualização e interiorização pelo crente, sendo, por isto, considerada como uma imagem de devoção. Por outro lado, esta também era, sem dúvida, uma imagem de culto (o que auxiliava a devoção) no sentido em que ganhava vida face aos rituais a ela ligados, ainda mais estando no ponto central da igreja. O ritual litúrgico e para-litúrgico medieval eram constituídos por um conjunto de estímulos sensoriais (luzes, incensos, objectos litúrgicos, palavras, gestos, ritmos ${ }^{67}$ ) que dotavam as imagens (elas próprias um estímulo sensorial) de um poder extremo, aumentando o seu efeito teofânico e mnemónico $^{68}$. O facto de a imagem abrir o seu manto, revelando a comunidade de crentes perto do corpo sagrado, poderia remeter para um relicário, à partida fechado, no momento que este revelava o seu interior. Esta ideia, de um acto de ocultação/revelação era propício a se enquadrar a toda a estrutura ligada aos ritos como uma epifania cruzando assim o rito à imagem. Esta ideia ganha força se pensarmos que o momento da visualização do que está oculto ganha um papel fulcral na Baixa Idade Média - século

\footnotetext{
${ }^{67}$ Sobre esta ideia ler DUFFY, Eamon in MARKS, Richard (Coord.) - Gothic: art for England, 14001547. London: V\&A publ., 2003, p.57

${ }^{68}$ A imagem ligada ao som e a palavra é determinante no exercício da memória. Para aprofundar esta questão SEVERI, Carlo - Op. cit., p.33
} 
XII/XIII - sendo o maior exemplo o papel fulcral a visualização da hóstia durante a $\operatorname{liturgia}^{69}$.

\section{O Papel do Paraíso e da Bem-aventurança na civilização cristã}

A terceira parte que compõe este "mosaico" é uma representação que ainda hoje suscita algumas dúvidas quanto à sua classificação temática. $\mathrm{O}$ seu estado deteriorado torna efectivamente a sua leitura difícil: um castelo de várias torres de onde saem figuras femininas (algumas parecem, paradoxalmente, masculinas) coroadas, entrelaçadas com filacteras onde estão inscritas em latim as Virtudes como, "VUMILLITAS", "DILIGENCIA"; “CARITAS" e "LARGITAS”, ou seja, estas figuras são uma alegoria às Virtudes. Dentro do castelo podemos ver uma fonte hexagonal (poderá ser a Fons Vitae?) junto à qual dois homens nimbados com vestes litúrgicas (poderão ser São Pedro e São Paulo?), que parecem acolher várias figuras que poderão ser à partida almas. Esta fortificação é protegida por um anjo com armadura e uma lança que poderá ser o Arcanjo Miguel protector das Jerusalém Celeste. Luís Urbano Afonso define-a como uma Jerusalém Celeste, já Paula Bessa considera que esta imagem poderá representar o Paraíso Terrestre onde os justos esperaram pelo Juízo Final ${ }^{70}$. A opinião desta autora baseia-se no facto de a muralha da Jerusalém Celeste, segundo o Evangelho de São João, possuir 12 portas com o nome das 12 tribos de Israel e 12 alicerces com o nome dos 12 apóstolos, enquanto a imagem de Bragança apenas apresenta uma porta. No entanto, não devemos esquecer que a visão que hoje temos da pintura é bastante fragmentária, não sendo possível fazer uma leitura iconográfica coerente a partir daquilo que ela omite; por outro lado questionamo-nos se a pintura terá que ser uma ilustração directa dos textos sagrados (estamos, no entanto, conscientes que o estilo e forma das pinturas são de uma grande erudição, provavelmente tendo em conta a circulação de artesãos). É ainda importante acrescentar que a representação das Virtudes nas imagens da Jerusalém Celeste não é algo inédito como demonstra o caso

\footnotetext{
${ }^{69}$ MARKS, Richard - Image and devotion in late medieval England. Stroud: Sutton, 2004, p.42 Para desenvolver esta ideia consultar, também DIDI-HUBERMAN, Georges - L'image ouverte: motifs de l'incarnation dans les arts visuels. Paris: Gallimard, 2007.

${ }^{70}$ BESSA, Paula - Op cit., 257
} 
da capela Notre-Dame de Benva e Lorgues ${ }^{71}$ (se bem que neste caso a Jerusalém Celeste é apresentada com motivos diversos aos de Bragança), sendo, por isso, provável a hipótese de se tratar de uma Jerusalém Celeste.

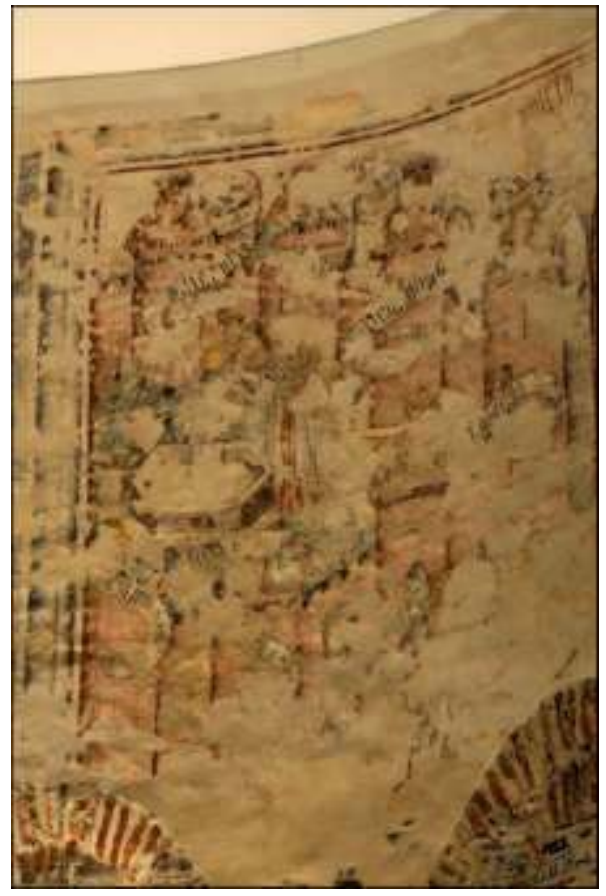

Fig.6 - Capela-mor da Igreja do Convento de São Francisco de Bragança - pintura mural da Jerusalém Celeste.

No entanto, outros argumentos relativos a uma leitura mais global das imagens da capela-mor de Bragança, surgem para corroborar a hipótese da representação de uma Jerusalém Celeste. Na introdução de Jean Delumeau da sua obra Que reste-t-il du Paradis?, o autor expressa a importância da noção de esperança no Paraíso (que explorará durante esta obra) como um pilar crucial na manutenção da cultura cristã. $\mathrm{O}$ autor apresenta uma linha lógica na sua obra que concorre para a importância da esperança na crença de uma bem-aventurança eterna para o Homem. Delumeau, propôs uma linha sequencial tendo começado com o tema do medo (explorado em obras como La Peur (1978); Le Péché et la peur (1983)); passando depois pelo sentimento de segurança (Rassurer et proteger (1989), L'Aveu et le Pardon (1990)) acabando em vários ensaios sobre as noções de bem-aventurança para a cristandade (Une Histoire du

\footnotetext{
${ }^{71}$ RIGAUX, Dominique - Op. Cit., p.199
} 
Paradis; Le Jardin des Délices (1992); Mille Ans de bonheur (1995) e por fim o Que reste-t-il du Paradis(2000) $)^{72}$. Ou seja, o autor vê que nos medos da Humanidade há uma necessidade de apaziguamento, sempre aliada a uma ideia de esperança de que estes medos cessem numa eterna bem-aventurança.

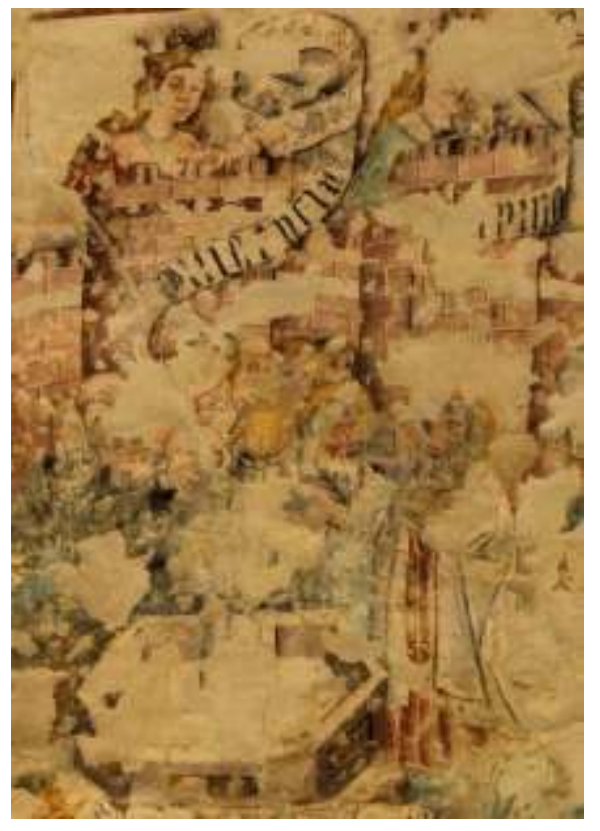

Fig.6 - Capela-mor da Igreja do Convento de São Francisco de Bragança - pintura mural da Jerusalém Celeste (pormenor).

Nos frescos brangantinos podemos ver esta concepção a partir do médium da pintura mural do estilo tardo-medievo, onde a Teofania Escatológica (Juízo Final) é catalisador de medos e esperanças; a Virgem do Manto serve como elemento profilático e apotropaico; e a Jerusalém Celeste representa a esperança na Bem-aventurança.

Parece-nos que esta bem-aventurança na Baixa Idade Média é bem expressa pela Jerusalém Celeste: esta é o fim último dos justos numa construção de tempo linear cristão, ao mesmo tempo que este tema é propício à criação e memorização (dentro do conceito de memoria medieval ${ }^{73}$ ) de imagens mentais. $\mathrm{O}$ facto de apresentar um lugar

\footnotetext{
${ }^{72}$ DELUMEAU, Jean - Que reste-t-il du paradis?. Paris: Fayard, 2000, p.9

73 Este conceito muito mais ligado à composição de imagens do que a simples retenção de ideias. CARRUTHERS, Mary J. - The craft of thought: meditation, rhetoric, and the making of images, 4001200. Cambridge: Cambridge University Press, 1998, p.3
} 
definido por muralhas e jardins joga com a dimensão espaço/lugar que segundo filosofo escolástico Dominicano Albertus Magnus (M.1280) é a melhor dimensão para fixar imagens na memória ${ }^{74}$. Segundo este autor a dimensão espaço/lugar só seria eficaz na sua associação metafórica ${ }^{75}$, como podemos ver o exemplo do caso da Jerusalém Celeste como metáfora para a bem-aventurança.

A percepção que o crente teria ao ver uma Jerusalém Celeste dentro destas imagens poderia perfeitamente ser a de esperança numa acção futura de que faria parte (dentro das almas acolhidas na Jerusalém Celeste). A um nível formal, a imagem da cabeceira que tem um maior dinamismo e narratividade é a da Jerusalém Celeste. Ou seja, esta narratividade e dinamismo explicitam a promessa de uma acção que decorrerá. Esta ideia perece-nos clara visto a imagem da Jerusalém Celeste, ao contrário das outras representações (Teofania Escatológica e Mater Omnium), não ser uma expectativa de uma promessa, é já, sim, a concretização de uma acção demonstrada na gestualidade viva e diversa das várias personagens envolvidas (podemos até encontrar uma interacção entre as duas representações nimbadas).

\section{Considerações Finais}

Se a interpretação por uma lógica programática faz sentido no caso das pinturas de São Francisco de Bragança, não podemos esquecer que a sua percepção pelo crente, apesar de ser global, é segundo o modo de memorização medieva ${ }^{76}$ feita por uma fragmentação do programa. O olhar capta apenas cada segmento aprendendo-o ${ }^{77}$ numa dialéctica isolada que poderá mais tarde ser completada com as outras imagens. Para esta visão global o facto de a igreja ser na Idade Média um espectáculo anagógico multissensorial deveria ajudar não só exaltar a devoção como ao mesmo tempo focar o espectador numa determinada imagem, bem como levá-lo a dispersar-se no conjunto visual que tinha perante si. Nesse sentido, pensamos estar a falar de um programa que apesar de ir beber a sua fundamentação à teologia, apenas tem/teve eficácia face à sua vertente

\footnotetext{
${ }^{74}$ Idem, Ibidem, .p.7

${ }^{75}$ Idem, Ibidem, .p.8

${ }^{76}$ Segundo os estudos de Mary Carruthers.

${ }^{77}$ CARRUTHERS, Mary J. - Op. cit., p.12
} 
profundamente antropológica, onde todo o Theatrum Sacrum ritualizado teve um papel crucial.

Tentamos a partir das pinturas murais de São Francisco de Bragança fazer uma reconstrução do papel do sujeito na percepção das imagens - estes simulacros só existem face a um sujeito que as visualiza/interioriza e lhes projecta significados. Sabemos, como referido inicialmente, da dificuldade que uma visão fenomenológica tem em se enquadrar no discurso historiográfico onde o papel etnográfico é profundamente limitado pela falta de contacto directo com o sujeito. No entanto, a história é sempre, como afirma Jacques Le Goff, uma construção interpretativa (como toda a Ciência Social) a partir dos objectos que possuímos. Nesse sentido caberá ao historiador (bem como a qualquer cientista social) tentar construir um discurso que possa não só englobar a conjuntura mas, também, o papel do sujeito, que é sempre quem lhe dá sentido.

\section{Bibliografia:}

AFONSO, Luís Urbano - As Pinturas Murais da Igreja do Convento de São Francisco de Leiria. Lisboa: Livros Horizonte, 2003.

AFONSO, Luís Urbano -"Manter a Freguesia no século XVI: Os frescos de São Francisco de Bragança e a Virgem da Misericórdia.”. Cadernos Terras Quentes, n², (2005).

AFONSO, Luís Urbano -A Pintura Mural Portuguesa entre o Gótico Internacional e o Fim do Renascimento. Formas, Significados, Funções. (tese de doutoramento defendida na Faculdade de Letras da Universidade de Lisboa) [Edição do autor], 2006.

BASCHET, Jérôme - La civilisation féodale. De l'an mil à la colonisation de l'Amérique. Paris : Flammarion, 2006.

BASCHET, Jérôme - Les justices de l'au-delà. Les représentations de l'enfer en France et en Italie (XII ${ }^{\mathrm{e}}-\mathrm{XV}^{\mathrm{e}}$ siècles). Rome : École Française de Rome Paris : 1993. 
BASCHET, Jérôme - L'iconographie médiévale. Paris : Gallimard, 2008.

BELTING, Hans - Image et culte : une histoire de l'art avant l'époque de l'art. Paris: Ed. du Cerf, 1998.

BELTING, Hans - L'Image et son Public au Moyen Age. Paris : G. Monfort, 1998.

BELTING, Hans - La vraie image: croire aux images ?, Paris: Gallimard, 2007.

BELTING, Hans - Pour une anthropologie des images. Paris : Gallimard, 2004.

BESSA, Paula - Pintura Mural no fim da Idade Média e início da Idade Moderna no Norte de Portugal. ( tese defendida na Universidade do Minho)[Edição da autora], 2007.

BOURDIEU, Pierre - Esboço de uma teoria da prática: precedido de três estudos etnologia Cabila. Oeiras: Celta Editores, 2002.

CAMILLE, Michael - The Gothic Idol: ideology and image-making in Medieval art. Cambridge: Cambridge University Press, 1989.

CARRUTHERS, Mary J. - The craft of thought: meditation, rhetoric, and the making of images, 400-1200. Cambridge: Cambridge University Press, 1998.

CHRISTIAN, William A. -Religiosidad local en la España de Felipe II. Madrid: Nerea, 1991.

DELUMEAU, Jean - Que reste-t-il du paradis?. Paris: Fayard, 2000.

DELUMEAU, Jean - Rassurrer et Protéger. Le sentiment de sécurité dan l'Occident d'autrefois. Paris: Fayard, 1989.

DESCOLA, Phillippe - "Manieres de voir, manières de figurer ». In DESCOLA, Philippe (Coord.), La Fabrique des images. Visions du Monde et formes de la représentation. Paris: Somogy (Musée du quai Branly), 2010.

DIDI-HUBERMAN, Georges - L'image ouverte: motifs de l'incarnation dans les arts visuels. Paris: Gallimard, 2007. 
DONADIEU-RIGAUT, Dominique - Penser en images les ordres religieux, XIIe-XVe siècles. Paris : Éditions Arguments, 2005.

DONADIEU-RIGAUT, Dominique «Les ordres religieux et le manteau de Marie ». Cahiers de Recherches Médiévales, (2001).

DUFFY, Eamon in MARKS, Richard (Coord.) - Gothic: art for England, 1400-1547. London: V\&A publ., 2003.

FOURNIÉ, Michelle - Le ciel peut-il attendre? Le culte du purgatoire dans le Midi de la France (v. 1320-v. 1520).Paris : Les Éd. du Cerf, 1997.

FREEDBERG, David e GALLESE, Vittorio "Motion, emotion and empathy in esthetic experience". Trends in Cognitive Science, Vol. 11, $\mathrm{n}^{\mathrm{o}}$ 5, (2007).

BASCHET, Jérôme - «Introduction : L' Image-Objet» in. SCHMITT, J.-C. e BASCHET, J. (Coord.) -L'Image. Fonctions et usages des images dans l'Occident médiéval. Paris : Le Léopard D’or, pp.7-26.

LE GOFF, Jacques - O Nascimento do Purgatório, Lisboa: Editorial Estampa, 1993.

LORD, Peter - The visual culture of Wales: Medieval Visions. Cardiff: University of Wales Press, 2003.

MARKS, Richard - Image and devotion in late medieval England. Stroud: Sutton, 2004.

MARTINS, Mário - Laudes e cantigas espirituais de Mestre André Dias. Roriz: Mosteiro de Singeverga, 1951.

HALBWACHS, Maurice - La mémoire collective. Paris: Albin Michel, 1997.

PANOFSKY, Erwin - Peinture et dévotion en Europe du Nord à la fin du Moyen âge. Paris: Flammarion, 1997.

RIGAUX, Dominique - Une mémoire pour l'avenir : peintures murales des régions alpines $=$ Una memoria per l'avvenire $:$ pitture murali delle regioni alpine. Novara: Interlinea, 1997. 
SCHMITT, Jean-Claude - La raison des gestes dans l'Occident médiéval. Paris: Gallimard, 1990.

SEVERI, Carlo - Le principe de la chimère : une anthropologie de la mémoire. Paris: Éd. Rue d'Ulm (Musée du Quai Branly), 2007.

\section{Fontes Web:}

ALBERT, J.-P. «L'histoire et l'anthropologie: convergences et spécificités». L'Atelier du Centre de recherches historiques. [Em linha]. №6 (2010) [Consultado a 8 de Abril de 2011] Disponível em 7 de Maio de 2010.

ANHEIM, Etienne «Art, littérature et anthropologie historique. Quelques réflexions historiographiques». L'Atelier du Centre de recherches historiques. [Em linha]. No6 (2010) [Consultado dia 8 de Abril de 2011] Disponível em 3 de Julho de 2010.

\section{COMO CITAR ESTE ARTIGO}

\section{Referência electrónica:}

LOPES, Inês Afonso - "O papel do sujeito face à imagem. Interpretações estruturofenomenológicas: o estudo de caso das pinturas murais de São Francisco de Bragança". Medievalista [Em linha]. №11, (Janeiro - Junho 2012). [Consultado dd.mm.aaaa]. Disponível em http://www2.fcsh.unl.pt/iem/medievalista/MEDIEVALISTA11 \lopes1110.html. ISSN 1646-740X. 


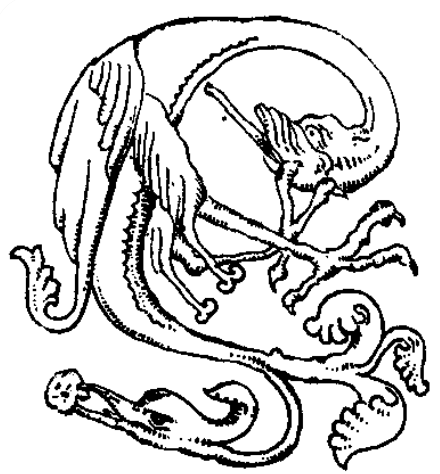

